\title{
Arte y promoción personal de un prelado durante el reinado de Felipe IV: el caso de Don Fernando de Andrade y Sotomayor.
}

\author{
Abel LOBATO FERNÁNDEZ
}

RESUMEN: El reinado de Felipe IV constituyó una época dorada para la cultura y el arte español. En este período ha de inscribirse la personalidad de don Fernando de Andrade y Sotomayor, quien llegaría a ser una importante figura religiosa y política. En el presente estudio se pretenden mostrar las diferentes acciones que llevó a cabo en el campo del arte y la cultura con el claro objetivo de destacar la antigüedad y grandeza de su linaje y procurar la obtención de prestigio u otros honores para sí mismo y sus familiares, algo habitual en este período de la Edad Moderna.

Palabras clave: Fernando de Andrade y Sotomayor; Obispo; arzobispo; convento; linaje; Vista Alegre; arte Barroco.

ABSTRACT: The reign of Philip IV represented a golden age for Spanish culture and arts, a period in which it shall be included Don Fernando de Andrade y Sotomayor, who would become an important religious and political figure during those years. The present essay tries to show the different initiatives that he carried out in the artistic and cultural fields. Most of them were aimed to highlight the antiquity and greatness of his lineage, and besides, obtaining prestige, or several honours for his family and himself, which was a very common behaviour in this period of the Early Modern times.

Keywords: Fernando de Andrade y Sotomayor; bishop; archbishop; convent; Vista Alegre; lineage; Baroque art.

\section{BREVE RESEÑA BIOGRÁFICA.}

Don Fernando de Andrade y Sotomayor nació en el Pazo de Vista Alegre el 23 de agosto de $1578 .{ }^{1}$ Fue el tercero de los quince vástagos que tuvo el matrimonio formado por don Rodrigo de Mendoza Sotomayor, señor de Villagarcía, Barrantes y Vistalegre y doña Urraca de Sotomayor Osorio².

\footnotetext{
${ }^{1}$ F. BOUZA-BREY TRILLO, El Señorío de Villagarcía desde su fundación hasta su marquesado (1461-1655), Santiago de Compostela, 1965, p. 85.

2 E. GONZÁLEZ LÓPEZ, El águila caída: Galicia en
}

Como segundón que era estudió la carrera eclesiástica en la Universidad de Salamanca ${ }^{3}$ y en 1603 viajó a Roma acompañando al VII Conde de Lemos con quien siempre mantuvo una estrecha relación. Tras la obtención del grado de doctor en la Universidad de Roma ${ }^{4}$, sirvió durante varios años en la $\mathrm{Cu}$ ria Pontificia hasta que, en 1609, se le prove-

\footnotetext{
los reinados de Felipe IV y Carlos II, Vigo, 1973, p. 347.

${ }^{3}$ Ibídem.

${ }^{4}$ M. R. PAZOS, El episcopado gallego a la luz de Documentos Romanos Tomo I, Madrid, 1946, p. 171.
} 
yó como Arcediano de Carrión y Canónigo de la catedral de Palencia. No pasaría ni un año de esto cuando, como él mismo explica: "volvimos a Roma a ser agente del reino de Nápoles siendo Virrey de él Don Pedro Fernández de Castro, Conde de Lemos y de Andrade" ${ }^{\prime \prime}$.

Andrade y Sotomayor no desaprovechó esta oportunidad y viajó de nuevo a la Ciudad Eterna, que desde el siglo XVI era un importante foco de atracción de artistas procedentes de todo el continente europeo. Durante su estancia Don Fernando pudo experimentar el fervor artístico y cultural que se respiraba en esta urbe a inicios del siglo XVII, donde es posible que visitara las colecciones papales y observara las numerosas obras artísticas de los más grandes maestros del Renacimiento y Manierismo que ornaban las iglesias, palacios y plazas de la ciudad. Por otro lado no hemos de olvidar que su relación con el noble Don Pedro de Castro también debió de ser otra gran influencia en Andrade y Sotomayor, puesto que aquél era un hombre culto, protector de artistas y literatos, gran amante del arte y promotor durante su estancia en Nápoles de una gran renovación cultural y urbanística ${ }^{6}$. Aparte de su labor como agente, durante estos años desempeñaría el cargo de Procurador General de las Iglesias de las dos Castillas ${ }^{7}$.

En 1616 abandonó definitivamente Roma para ocupar un canonicato en la seo sevillana otorgado por el Papa Paulo $\mathrm{V}^{8}$. Por aquél entonces Sevilla era una "ciudadmundo" ${ }^{\prime \prime}$, verdadero foco cultural dentro del

\footnotetext{
5 Archivo Histórico Provincial de Burgos (desde aquí AHPB.) Protocolos de Burgos, Oficio de Domingo de Loyola, 25 de noviembre de 1633, caja 6332, fol. 752 v.

${ }^{6}$ E. PARDO DE GUEVARA Y VALDÉS, Don Pedro Fernández de Castro VII Conde de Lemos. Estudio histórico. A Coruña, 1997. p. 276.

${ }^{7}$ E. GONZÁLEZ LÓPEZ, op. cit., p. 347.

${ }^{8}$ AHPB, Protocolos de Burgos, Oficio de Domingo de Loyola, 25 de noviembre de 1633, caja 6332, fol. 753 r.

${ }^{9}$ L. MÉNDEZ RODRÍGUEZ, Velázquez y la cultura
}

reino, que mantenía abierto un vivo comercio artístico con otros centros productivos como la Corte madrileña, Italia o los Países Bajos ${ }^{10}$. La experiencia romana, así como su estancia en la ciudad del Guadalquivir, resultarían decisivas a la hora de configurar su gusto artístico y su afán por el coleccionismo. En su condición de canónigo, tuvo ocasión de formar parte de una institución que funcionaba como centro productor y generador de tendencias, jugando un importante papel en el progreso cultural de la ciudad ${ }^{11}$. La catedral contenía obras de los más afamados artistas hispanos del momento, como Francisco Pacheco o Martínez, que sin duda él vería. Por otra parte, no hay que olvidar que durante estos años se inició el despegue de tres grandes maestros de la pintura: Zurbarán, Alonso Cano y Velázquez, a los que tal vez pudo conocer $^{12}$. En Sevilla fue testigo de diversos acontecimientos, como el renombrado voto a la Inmaculada Concepción en diciembre de 1617 o las fastuosas exequias reales de Felipe III en junio de 1621, para el que se levantó un impresionante túmulo que sin duda dejarían en él una profunda huella ${ }^{13}$. También sabemos que, a pesar de las diversas disposiciones contra la presencia "oficial" del clero en los corrales de comedia, el canónigo Andrade era aficionado al teatro, pues frecuentó el de Doña Elvira, uno de los tres existentes por aquel entonces en la ciudad ${ }^{14}$.

sevillana, Sevilla, 2005, p. 27.

${ }^{10}$ E. VALDIVIESO, Catálogo de las pinturas de la Catedral de Sevilla, Valladolid, 1977, p. 10.

${ }^{11}$ F. QUILES, Teatro de la gloria, el universo artístico de la Catedral de Sevilla en el Barroco, Sevilla, 2007, p. 13-20.

12 Zurbarán (1568-1664) residió en Sevilla durante su período de aprendizaje, entre 1614 y 1617 ciudad en a que se avecindaría de nuevo en 1627 . Por su parte, Alonso Cano (1601-1667) residió en Sevilla entre 1614, cuando inicia su período de formación y 1638, mientras que Velázquez (1599-1660), abandonó la ciudad del Guadalquivir en 1623.

13 J.M. BAENA GALLÉ, Exequias reales en la Catedral de Sevilla durante el siglo XVII, Sevilla, 1992, pp. 71-76.

${ }^{14}$ P. BOLAÑOS DONOSO, "Para tal palo, tal astilla. Sobre el Corral de Comedias "Doña Elvira" y Diego de 
En 1623 accedió al cargo de Arcediano de Écija ${ }^{15}$, y ya desde entonces la influencia que su tío, Antonio de Sotomayor, Consejero de Estado y futuro Inquisidor General, ejerció sobre Felipe IV, facilitaría su ascenso a cargos eclesiásticos cada vez más importantes. Su respaldo facilitó que Su Majestad le nombrase en agosto de 1625 Capellán Mayor de la Capilla Real, uno de los puestos más codiciados en la seo sevillana ${ }^{16}$. Esta brillante carrera prosiguió con la designación como Inquisidor Apostólico de Sevilla en 1626, a lo que pronto se le uniría el título de Visitador ${ }^{17}$, cargos todos ellos que desempeñaría hasta su nombramiento como obispo de Palencia en 1628.

En la ciudad hispalense, don Fernando de Andrade adquirió algunas piezas de platería, posiblemente destinadas a uso doméstico, según se desprende de su primer testamento, redactado unos años después en la ciudad de Burgos:

[...] y dos fuentes de plata y otras dos piezas de plata doradas que compramos siendo canónigo en la santa iglesia de Sevilla. ${ }^{18}$.

Tras su nombramiento como obispo de Palencia, fue consagrado en Sevilla el 10 de septiembre de 1628, aunque no llegó a su nuevo destino hasta dos meses más tarde ${ }^{19}$. Poco más de tres años rigió la sede palentina, pues en 1632 Felipe IV lo propuso para ocupar la diócesis de Burgos ${ }^{20}$. A principios

Almonacid (1624-1627)" Actas de la XV Jornadas de Teatro del Siglo de Oro, Almería, 2001 p. 154.

15 T. MINGUELLA Y ARNEDO, Historia de la Diócesis de Sigüenza y de sus obispos. Vol. 3, Madrid, 1910-1913, p. 39 .

16 AHPB, Protocolos de Burgos, Oficio de Domingo de Loyola, 25 de noviembre de 1633, caja 6332, fol. 753 r.

17 A. ÁlVAREZ REYERO, Crónicas Episcopales Palentinas, Palencia, 1898, pp. 296-297.

18 I. GARCÍA RÁMILA, op. cit., p. 27.

19 Ibídem. p. 297

${ }^{20}$ Archivo Histórico de la Catedral de Burgos (desde aquí AHCB), Actas Capitulares, CB RR-82 fols. 49 v. -50 r. de 1637 el monarca designó a nuestro arzobispo como Virrey y Capitán General de Navarra $^{21}$. Para que pudiese desempeñar su nuevo cometido, el Papa Urbano VIII envió un Breve en el que le daba licencia para ausentarse por un año de su diócesis ${ }^{22}$. Don Fernando de Andrade tuvo un destacado papel en la defensa de la franja navarra durante el ataque francés retornando a su sede el 5 de abril de $1638^{23}$.

No mucho tiempo después el monarca le dio el puesto político de Presidente del Consejo de Cantabria, cargo que ya ejercía en agosto de $1639^{24}$. A finales de septiembre de ese mismo año debió de enfermar gravemente, razón por la que el dos de octubre dictó su primer testamento, aunque logró restablecerse unos días después ${ }^{25}$.

${ }^{21}$ E. GONZÁLEZ LÓPEZ, op. cit., p. 347.

22 G. GONZÁLEZ DÁVILA, Teatro eclesiástico de las iglesias metropolitanas y catedrales de los Reynos de las dos Castillas, vidas de sus arzobispos y obispos y cosas memorables de sus sedes, Tomo I Madrid, 1645, p. 128.

23 R. RODRÍGUEZ GARRAZA, "Los intentos de extensión en Navarra del servicio militar (siglo XVIII)", Iura vasconiae: revista de derecho histórico de Vasconia $N^{o}$ 2, 2003, p. 367.

24 AHPB, Protocolos de Burgos, Oficio de Domingo de Loyola, 2 de octubre de 1639, Caja 6337, fols. 391396. Debido a la imposibilidad de consultar el original por su precario estado de conservación, se ha tomado para este trabajo la transcripción que hizo I. GARCÍA RÁMILA: "Del Burgos de antaño : curiosos antecedentes genealógicos y familiares de D. Fernando de Andrade y Sotomayor, Arzobispo que fue de la ciudad de Burgos de 1632 a 1639, y testamento otorgado por dicho Excelentísimo señor el día 2 de octubre de 1639", Boletín de la Comisión Provincial de Monumentos y de la Institución Fernán González de la ciudad de Burgos, 1949, Año 28, № 106, pp. 18-30 (Protocolo № 3026 fol. 391 a 396).

${ }^{25}$ Aparte de este primer testamento dictado en Burgos, a lo largo de su vida dictó otros dos testamentos, uno en Sigüenza, el 1 de agosto de 1644 ante el escribano Bernardo Sedeño, hoy no conservado y el último otorgado en Santiago de Compostela ante Domingo Leirado, el 27 de marzo de 1652, y su codicilo, ante el mismo notario el 20 de enero de 1655 y cuya transcripción se puede encontrar en: F. BOUZA-BREY TRILLO, “Testamento y codicilo del Arzobispo de Santiago D. Fernando de Andrade y Sotomayor", Boletín da Real Academia Galega, colección de documentos históricos Tomo 
Conocido en septiembre de 1640 su nombramiento como obispo de Sigüenza, abandonó Burgos para entrar en su nueva sede el 15 de octubre. Rigió la diócesis seguntina durante casi 5 años, hasta marzo de 1645 en que fue promocionado al arzobispado de Santiago de Compostela. ${ }^{26}$

Su etapa compostelana estuvo marcada por la guerra con la vecina Portugal ${ }^{27}$. A pesar de su avanzada edad, entre $1647 \mathrm{y}$ 1648 ocupó de manera interina el cargo de gobernador y capitán general de Galicia, logrando mantenerla a salvo de los portugueses. Murió en Santiago de Compostela el 22 de enero de 1655, y fue enterrado en el corredor que media entre el coro y la Capilla mayor ${ }^{28}$.

\section{LIBERALIDAD DE DON FERNANDO DE ANDRADE Y SOTOMAYOR VINCULADA A SU PAPEL COMO PRELADO (1628-1655).}

Nada más llegar a Palencia, Andrade y Sotomayor hubo de pedir prestados al cabildo 2.000 ducados, ya que "venía algo falto de hacienda por los grandes gastos que ha tenido y no poderlos sacar de los frutos de sus rentas" ${ }^{29}$. Esta precariedad económica debió desaparecer una vez comenzó a recibir los frutos y rentas que le correspondían como obispo palentino, decidiendo participar un año después en la mejora del acceso al lugar destinado a la custodia de los documentos y libros de la catedral ${ }^{30}$. Dicha in-

\footnotetext{
II, pp. 98-120.

${ }^{26}$ M. R. PAZOS, op. cit., p. 174.

${ }^{27}$ E. GONZÁLEZ LÓPEZ, op. cit., p. 347.

${ }^{28}$ A. LÓPEZ FERREIRO, Historia de la Santa Apostólica Metropolitana Iglesia de Santiago, Tomo IX, Santiago de Compostela, 1898, pp. 122-125.

${ }^{29}$ Archivo de la catedral de Palencia (desde aquí ACP), Actas Capitulares, Tomo 1628-1631, fol. 41 v.

${ }^{30}$ S. FRANCIA LORENZO, "La Memoria y el Saber. El Archivo y la biblioteca Capitulares", La catedral de Palencia, catorce siglos de historia y arte, Burgos, 2011, p. 538.
}

tervención se materializó en la construcción de unas puertas nuevas que dignificasen el acceso a la Contaduría y al Provisorato ${ }^{31}$. En dichas puertas aparece la fecha "1629" y lo que es más importante, el escudo del obispo Andrade y Sotomayor junto con el del cabildo, muestra de que ambos fueron los patrocinadores de la obra. Se trata de unas puertas con un hueco central donde se inserta una portezuela decorada con los motivos heráldicos y cuatro barrotes de metal. El encasamiento de la misma es muy sencillo, conformando una distribución en cruz alrededor de dicha portezuela. En las esquinas, se insertan tableros de madera más oscura decorados con motivos vegetales e inscripciones que indican el lugar al que se accede por ellas.

Conocido su nombramiento en noviembre de 1631 como arzobispo de Burgos, una comisión del cabildo burgalés fue a darle la enhorabuena a Palencia. Andrade y Sotomayor, como símbolo de buenas intenciones, les regaló "unos cordones de oro con pendientes de reliquias y unos guantes de ámbar" ${ }^{32}$, sin duda con la intención de tener una acogida favorable entre sus futuros subordinados y esperar de ellos contrapartidas, que se iniciaron con la entrega de un "guión de plata" por parte del cabildo ${ }^{33}$. Este báculo permaneció en su poder hasta su muerte, a pesar de que según lo estipulado, debería haberlo devuelto tras su promoción a la diócesis de Sigüenza ${ }^{34}$.

El origen de este espacio hay que buscarlo a mediados del siglo XVI, cuando se llevó a cabo su construcción al lado del claustro. Éste constaba de tres salas dedicadas a Archivo y Contaduría y una más, para guardar la documentación del Provisorato. Las tres salas tuvieron que ser reconstruidas tras su desplome el 26 de febrero de 1703.

\footnotetext{
31 S. FRANCIA LORENZO, op. cit., p. 542.

${ }^{32}$ AHCB, Actas Capitulares, RR-81 fols. 629 v. -630 r.

${ }^{33}$ AHCB, Actas Capitulares, RR-81 fol. 690 r.

${ }^{34}$ A su muerte, el Cabildo burgalés reclamaría al de
} Santiago su devolución en varias ocasiones, todas ellas de manera infructuosa. 
Como arzobispo de Burgos nuestro prelado ejerció un importante papel en la ejecución de obras destinadas al culto y uso litúrgico de la catedral, aunque no siempre conforme a los plazos tradicionalmente establecidos. Así, ya desde el siglo XV, era costumbre entre los arzobispos burgaleses regalar un terno con motivo de su toma de posesión ${ }^{35}$. En el caso de don Fernando de Andrade su entrega se dilató enormemente en el tiempo, pues ocho años después de su llegada a Burgos aún no lo había encargado, tal y como se expresa en una de sus mandas testamentarias por la que disponía hacer el terno rico que por obligación debía donar a la catedral ${ }^{36}$. A pesar de ello, un año después seguía sin iniciarse su confección, puesto que al conocerse su nombramiento en septiembre de 1640 como obispo de Sigüenza, el cabildo burgalés, temeroso de que el prelado partiese sin haber cumplido con la entrega, le reiteró "la obligación que su Ilustrísima tiene con la santa iglesia catedral de Burgos de entregar un terno rico, como todos sus antecesores" ${ }^{37}$. Para calmar a los canónigos, el prelado prometió su hechura, ofreciendo 1.000 ducados $^{38}$. Ante la imposibilidad de su fabricación en los talleres catedralicios debido a la marcha del arzobispo, el cabildo dejó claro cómo debía ser ese terno rico:

Que las ocho capas del terno rico que se hace a cargo del arçobispo Fernando de Andrade Sotomayor a que esta obligado, sean iguales a la medida de las 40 capas que dio el cardenal Antonio Zapata ${ }^{39}$.

\footnotetext{
${ }^{35}$ M. NEGRO COBO, "La riqueza de una basílica. El museo y las colecciones de la catedral de Burgos", en La catedral de Burgos, ocho siglos de historia y arte, Burgos, 2008, p.493.

${ }^{36}$ I. GARCÍA RÁMILA, op. cit. p. 24.

${ }^{37}$ AHCB. Actas Capitulares, RR-83 fol. 333 r.

${ }^{38}$ AHCB, Ibídem.

${ }^{39}$ AHCB, Actas Capitulares, RR-83 fols. 474 v.-475 r.
}

El de Zapata era uno de los conjuntos textiles más suntuosos y bellos de la catedral, y con este mandato el cabildo se aseguraba de que lo que don Fernando de Andrade enviase desde Sigüenza sería de calidad y a juego con el legado del cardenal. Meses más tarde, concretamente en diciembre de 1641 el nuevo arzobispo-obispo de Sigüenza remitió a Burgos el terno rico, compuesto por "ocho capas de tela rica, casulla, dalmáticas y dos frontales" ${ }^{\prime 4}$. Tal vez para compensar la demora en la entrega del terno, el prelado incluyó en la dádiva esos dos frontales, a los que se habría de sumar otro más de brocado que con destino al altar mayor regaló un año después ${ }^{41}$.

También cabe reseñar su colaboración para la adquisición en noviembre de 1633 de una "colgadura rica" con destino a la capilla mayor de la catedral, cuyo promotor y máximo donante fue el cardenal Zapata ${ }^{42}$. Tal y como le correspondía como arzobispo de Burgos, Andrade y Sotomayor se mostró siempre preocupado por el ornato y enriquecimiento artístico de la catedral.

Otro de los aspectos en los que el prelado colaboró durante su mandato como arzobispo de Burgos fue en la construcción de los dos nuevos órganos de la catedral burgalesa. Los órganos del siglo XVI situados a ambos lados del coro, habían sufrido diversos arreglos durante el primer tercio del siglo XVII hasta que finalmente se vio la necesidad de renovarlos. Por ello, el 13 de marzo de 1636 el cabildo estudió y aceptó un proyecto que el organista Juan de Argüete había presentado para la construcción de un nuevo instrumento, presumiblemente el de la Epístola, indicando que "su traza vendrá

\footnotetext{
${ }^{40}$ AHCB, Actas Capitulares, RR-83 fol. 537 r.

41 AHCB RR-83 585 v.

42 A. BLANCO DÍEZ, Amancio. "Adición a los li-
} bros impresos burgaleses: Proyección de recuerdos de la primera mitad del siglo XVII (10)", Boletín de la Comisión Provincial de Monumentos y de la Institución Fernán González de la ciudad de Burgos, 1950, p. 116. 
a ser la mejor que haya en estos reinos." ${ }^{43}$. Inmediatamente el cabildo se puso a buscar el dinero necesario para su construcción. Diez y ocho días después, se llevaban ya recaudados casi 12.000 ducados, de los que el arzobispo había dado la cantidad de $5.500^{44}$. Su participación en esta obra hemos de contemplarla como parte de su apoyo y respaldo a la liturgia tridentina, $\mathrm{y}$ al impulso que la música sacra estaba cobrando dentro de las celebraciones religiosas del barroco hispano.

Por esa misma razón, en 1638, una vez terminado el órgano de la Epístola el cabildo se animó a renovar también el del Evangelio, obra que posiblemente se le encargaría de nuevo a Argüete ${ }^{45}$. También en esta ocasión se contó con la colaboración económica del prelado. Así, tras devolver los 3.000 ducados que le había prestado la fábrica catedralicia cuando fue nombrado virrey de Navarra, añadió como agradecimiento 300 más con destino a la "mejora de los tubos del órgano colateral que se a puesto para la correspondencia del órgano que se ha echo nuevo" ${ }^{46}$.

Estos órganos sufrieron a principios del siglo XVIII notables arreglos para acomodarlos a la nueva estética que se estaba imponiendo por entonces. El encargado de llevar a cabo esta tarea fue José de Echevarría, sobrino del afamado fray José de Echevarría, quien refeccionó el de la Epístola (1704-1706) y el del Evangelio (1708-1710) conservando de los primigenios solamente su caja ${ }^{47}$. Ambos órganos serían reformados de nuevo en el siglo XIX ${ }^{48}$.

\footnotetext{
${ }^{43}$ M. MARTÍNEZ Y SANZ, Historia del templo catedral de Burgos: escrita con arreglo a documentos de su archivo, Burgos, 1866, p. 77.

${ }^{44}$ J. LÓPEZ CALO, op. cit., p. 565.

45 Ibídem.

${ }^{46}$ AHCB, Actas Capitulares, RR-83 fol. 199 r.

47 J. LÓPEZ CALO, op. cit., p. 578.

${ }^{48}$ Ibídem, p. 583.
}

En la actualidad solamente se conserva la caja del órgano de la Epístola (fig. 1), de una gran sencillez y elegancia, dividida en dos cuerpos y ático, en cuyos dos extremos aparecen sendos angelotes portando los escudos del propio cabildo y del prelado (fig. 2). Las calles, en las que se sitúa parte de la tubería, se separan mediante pilastras cajeadas, y en la central del primer cuerpo aparece inscrito " 1636 ", la fecha de su construcción. Cada calle culmina en semifrontones con volutas, y acróteras coronados por pirámides y bolas a excepción del central que termina en un frontón semicircular, y una gran acrotera con una cruz. La colocación del escudo de Andrade y Sotomayor en la caja del órgano fue decisión del cabildo burgalés como expresión de su agradecimiento hacia el prelado por su importante contribución económica en la construcción. Estilísticamente esta obra guarda ciertas similitudes con los dos órganos de la excolegiata de San Pedro de Lerma, hechos por Diego Quijano entre $1615-1617^{49}$.

El 21 de diciembre de $1637^{50}$, el rey Felipe IV, con la más que probable influencia del Conde-Duque de Olivares, designó a don Fernando de Andrade y Sotomayor Virrey y Capitán General de Navarra. Nombrados por el rey, y a las órdenes directas del arzobispo estuvieron los ingenieros militares Marco Antonio Gandolfo, Jerónimo de Soto y Pedro Teixeira ${ }^{51}$. Por mandato del prelado -en su papel como Virrey y Capitán general de Navarra-, realizaron varias plantas y planos, de los cuales se conservan actualmente cuatro; se trata por una parte las vistas panorámicas de los dos valles de Carlos y Baztán, con pequeñas representaciones de los "fuertes" abaluartados de Burguete y Maya; por otra parte, dos planos del fuerte de la villa

\footnotetext{
${ }^{49}$ A. DE VICENTE, El órgano de la colegiata de Lerma, historia y restauración, Valladolid, 1996 p. 7.

${ }^{50}$ A. ÁLVAREZ REYERO, op. cit., p. 297.

51 F. PEREDA y F. MARÍAS, El Atlas del Rey Planeta, Madrid, 2008, p. 16. P.
} 
de Burguete, uno de ellos firmado por el propio Teixeira, conservados en el Archivo General de Simancas ${ }^{52}$. Por desgracia, no se ha conservado ningún testimonio gráfico de los proyectos que el arzobispo les mandó llevar a cabo para la fortificación de la ciudadela de Pamplona.

Mención aparte merece la donación de una lámpara de plata que don Fernando de Andrade hizo siendo arzobispo de Burgos con destino a la Capilla del Santo Cristo de la catedral de Orense, imagen que gozó de una gran devoción en la España Barroca. Por su primer testamento, sabemos que en ese momento tenía encargada "una lámpara de peso de cuatrocientos ducados de plata, la cual está en poder de Andrés de Alvear, platero labrándose para remitirla al Santo Cristo de Orense" 53 .

Dicha lámpara (Fig. 6), no llegó a su destino hasta 1644, pues el arzobispo no debió de quedar conforme con la obra final del platero burgalés y decidió renovarla en Madrid $^{54}$, sede de la Corte y donde trabajaban algunos de los mejores plateros del momento, aunque desconocemos cuál de ellos llevó a cabo la modificación, que consistió en la añadidura de unas aletas y unas cornucopias realizadas también en plata, y decoradas con repujado de tipo vegetal de gran belleza ${ }^{55}$. Para que quedase constancia de su donación, mandó grabar su escudo a ambos lados de la lámpara (fig. 7). El arzobispo se preocupó además de su dotación, destinando en un primer momento 250 ducados $^{56}$, aunque fi-

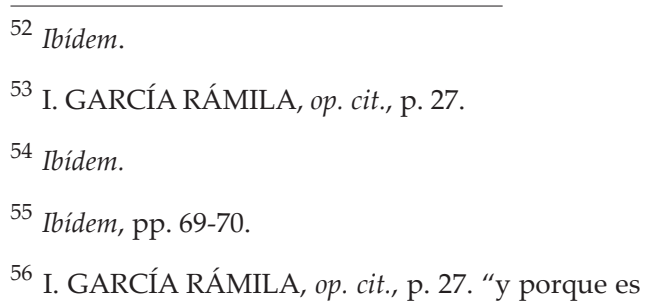
obligación precisa nuestra el dar y dotar esta lámpara queremos que de lo mejor parado de nuestros bienes se saquen ducientos y cinquenta ducados y se entreguen a los señores Deán y Cabildo de la Santa Iglesia de la dicha ciudad para que se pongan en renta para aceite que arda en dicha lámpara perpetuamente". nalmente alcanzó la cifra de los $400^{57}$. Esta pieza, es una de las de mayor calidad de la capilla, y tras su recepción fue colgada en medio del arco de la capilla mayor, lugar en el que continúa en la actualidad.

Una vez fue promovido a Sigüenza en 1640, las crecidas rentas de su nueva diócesis le permitieron emprender nuevas acciones relacionadas con el arte. Así, el 16 de agosto de 1642, sobre las 7 y media de la tarde, una gran tormenta se abatió sobre la ciudad de Burgos, causando grandes destrozos. Los daños en la fábrica catedralicia fueron notables: rotura de todos los chapiteles del cimborrio, hundimiento de parte de la cubierta, quiebra de los chapiteles de la Capilla del Condestable y rotura de pináculos y gárgolas en la fachada de Santa María ${ }^{58}$. Por mediación del conde de Montalvo, vino a Burgos el arquitecto real Juan Gómez de Mora, que realizó una valoración de los daños subrayando la necesidad urgente de su restauración ${ }^{59}$. El alto coste de estas obras motivó que se pidiese ayuda económica a numerosas personalidades e instituciones del reino. Don Fernando de Andrade prometió destinar 4.000 ducados para la "reconstrucción de las torres y crucero [...] que se hallaban arruinados" ${ }^{\prime 60}$, cuya escritura de donación se hizo el 27 de octubre de 1642 , solamente dos meses después del grave suceso. En su último testamento, el prelado alude a que el cabildo, agradecido por esta donación y su intervención en la construcción de los órganos catedralicios, decidió fundar y dotar una misa cantada en su honor en la festividad de la octava de Santiago Apóstol, así como "otras demostraziones de que se pongan nuestras Armas en la parte de la obra que se reedificó" 61 .

${ }^{57}$ M. R. PAZOS, op. cit., p. 179.

58 J. MATESANZ DEL BARRIO, “De los Resplandores barrocos a las Luces de la Razón, La Catedral de Burgos durante los siglos XVII y XVIII", en La catedral de Burgos, ocho siglos de historia y arte, Burgos, 2008, p. 322.

\footnotetext{
${ }^{59}$ Ibídem.

${ }^{60}$ AHCB, Varios 58 fols. 169 r. 170 v.

${ }^{61}$ F. BOUZA-BREY TRILLO, op. cit., p. 104
} 
Respecto a la colocación de sus armas en la parte reconstruida tras el temporal que menciona en su testamento, hasta el momento no se ha podido encontrar ninguna otra referencia ni indicio. Las obras de reconstrucción y reparación de los elementos dañados por el vendaval fue llevada a cabo entre 1643 y 1644 por artífices de procedencia mayoritariamente cántabra y dirigidos por Juan Rivas del Río en lo relativo a la arquitectura, y con la colaboración de varios escultores como Juan de los Helgueros y Juan de Pobes que fabricaron de nuevo algunos ángeles, santos y los elementos que había perdido la escultura de Santiago Matamoros $^{62}$ (fig. 3).

Por lo que respecta a la propia ciudad de Sigüenza, su devoción a las reliquias de Santa Librada, patrona de la ciudad, movió a don Fernando de Andrade a llevar a cabo una restauración del conjunto conformado por el retablo, sepulcro de don Fadrique de Portugal, Puerta del Jaspe, Puerta de la Sacristía y las rejas que lo rodeaban así como el dorado y pintado de los tornavoces de los dos púlpitos de la Capilla Mayor ${ }^{63}$. Este espacio (fig. 4), situado en el extremo del transepto norte, era uno de los más importantes de la catedral y ya había sido remodelado hacia 1520 por mandato el obispo don Fadrique ${ }^{64}$.

Para llevar a cabo dicha restauración del conjunto cultual y funerario se llamó al pintor Jerónimo de Aparicio, avecindado en

62 J. MATESANZ DEL BARRIO, op. cit., p. 322.

${ }^{63}$ La capilla de Santa Librada resultó seriamente dañada durante el asedio que sufrió la catedral entre el 8 y el 15 de octubre de 1936, y tras su restauración se eliminó la reja. Además el hundimiento de la cúpula tras los bombardeos destruyó por completo ambos tornavoces. Para más información acerca de estos elementos: A. FEDERICO, La catedral de Sigüenza, Madrid, 1954. y J. JUSTE BALLESTA y E. BARCELÓ, “El plan director de la catedral de Sigüenza", Bienes culturales: revista del Instituto del Patrimonio Histórico Español, №1, 2002, pp. 55-80.

64 P. NAVASCUÉS PALACIO, "La catedral de Sigüenza", Catedrales de España, Espasa Calpe, 1999, p.89.
Sigüenza y que ya había realizado con anterioridad otras obras para la catedral ${ }^{65}$. El contrato entre el prelado y el pintor se firmó en la fortaleza episcopal el 14 de diciembre de 1643. Como fiador del artista figuraba Lorenzo Serantes de la Peña "vecino y regidor perpetuo de la villa de Atienza"66. Mientras que acompañando al arzobispo-obispo aparecía el deán, don Lorenzo Francés de Urrutigoyti. En este documento se expresa claramente cómo el obispo:

[...] a acordado y quiere para su debocion se pinte y dore la obra del retablo y rexas y lo demas anexo de la capilla del cuerpo de señora Sancta Librada Patrona deste obispado sita en la Sancta. Yglesia catedral desta dicha ciudad y las copulas de los dos pulpitos del altar mayor de ella a costa de su Ylustrisima ${ }^{67}$.

El precio convenido fue de 8.800 reales que se entregarían de la siguiente manera: 3.000 reales en el momento de iniciar el trabajo para materiales, 3000 mediada la obra y los últimos 2.800 una vez terminada y reconocida por oficiales nombrados por parte del arzobispo-obispo, quien además correría con el gasto que tuviese la hechura y colocación de los andamios. La intención de Andrade y Sotomayor era respetar escrupulosamente los colores y motivos decorativos que tenían los elementos originales, así como reparar las faltas y defectos que tuviesen las labras de los espacios a restaurar ${ }^{68}$.

${ }^{65}$ M. PÉREZ-VILLAMIL, La Catedral de Sigüenza erigida en el siglo XII con noticias nuevas para la historia del arte en España, sacadas de documentos de su Archivo, Madrid, 1899, p. 189. Esta imagen desapareció en el siglo XVIII tras su sustitución por un relieve con la imposición de la casulla a San Ildefonso.

66 Archivo Histórico Provincial de Guadalajara, (desde aquí AHPG), Protocolos de Sigüenza, Oficio de Bernardo Sedeño, 14 de diciembre de 1643, caja 2196, s/f.

${ }^{67}$ Ibídem.

${ }^{68}$ AHPG, Protocolos de Sigüenza, Oficio de Bernardo Sedeño, 14 de diciembre de 1643, caja 2196, s/f. " “1 Es condición que todo el retablo de la Sancta y colaterales de los dos lados y puerta de la sacristía se a de dorar de muy buen oro mate que quede mui lustroso advirtiendo que las partes donde ubiere deborado algun pedaço de 
Respecto a los tornavoces, se deberían "dorar de oro bruñido sobre sus muy buenos aparejos y estofar conforme al arte y parte que piden dichas copulas".

Por otro lado, la reposición de las partes de las imágenes que faltasen o estuviesen deterioradas correría "por cuenta del pintor el echarlas y dejarlas con toda perfección" ${ }^{\prime 69}$, mientras que los reparos de la reja que protegían la capilla sería "por cuenta de su Ilustrísima [...] y se ha de dar reparada antes de entrarla a pintar"70

De nuevo, Andrade y Sotomayor emprendía una importante labor de promoción artística en este caso ideada por él mismo y asociada a su papel como prelado. Las obras terminaron siete meses después, en julio de 1644 y el Cabildo, agradecido, le invitó a la catedral a "la Comedia que se ha de hacer en ella [...] y que dicho día jueves se diga una misa solemne en parte de gratitud a los favores que su Ilustrísima hace al cabildo y a esta su santa Iglesia y señora santa Librada"71. Además decidió crear una memoria perpetua en su honor cada año "el día y por quien y de el modo que su Ilustrísima señalare y ordenare"72. Andrade y Sotomayor complacido, decidió que esa dotación fuese para la festividad de San Carlos $^{73}$. Además el Cabildo, deseoso de satisfacer al prelado tras su importante labor de patrocinio con la catedral ordenó que:

cornisa se a de coxer de oro o color sigun lo pidiere la obra fingiendolo de manera que el defeto que en dicho retablo hubiere se repare por este camino de manera que quede dicho retablo y colaterales con la perfección que pide de dicha obra perfilando de negro o sombra las partes donde lo pidiere la obra en la conformidad que parece estaba según demuestra dicha obra."

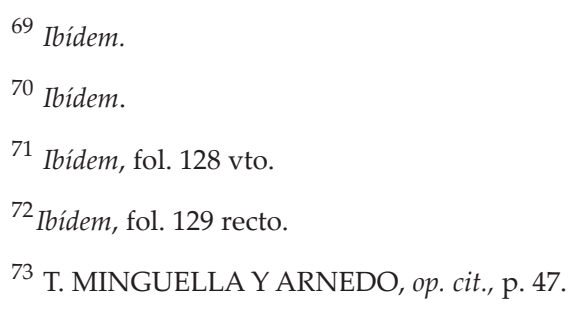

[...]de las cinco reliquias de dicha sancta que están en la caja de plata, en la peana adonde esta la cabeça de la Sancta se le ofrezca a su Ylustrisima y se le de la que quisiere escoger [...] en señal de amor y de agradecimiento a la liberalidad piedad y devoción que tiene su Ylustrisima con nuestra. Sancta. Patrona ${ }^{74}$.

Esta reliquia, "don de Grandísima estimación nuestra"75 en propias palabras del prelado, la depositaría años más tarde en el Convento de Vista Alegre que fundó en Villagarcía de Arosa, su localidad natal.

Como constancia de esa importante labor restauradora, se colocaron en la fachada del Altar de Santa Librada dos cartelas rectangulares con sendas inscripciones (fig. 5). En la de la izquierda:

"ILMVS. ET RMVS. D. D. FERDI-
NAND, DE ANDRADE ET SOTO
MAIOR. ARCHEPVS. AC. DNus.
SAEG."

Y en la de la derecha:

\section{“ARDENTI ZELO SVSCITAV AVRUM ET PICTVRA SOCIAN FORMOSVM REDIDIT OP."77}

Antes de abandonar definitivamente la ciudad de Sigüenza, y como ocurrió con todos sus predecesores, se tasaron los desperfectos producidos durante su gobierno en los castillos y edificaciones adscritos a la mitra. Una comisión era la encargada de inspeccionarlos y redactar una memoria en la que se expresaban los daños existentes y los reparos necesarios que debían ser sufragados por

\footnotetext{
${ }^{74}$ Archivo de la catedral de Sigüenza, (desde aquí ACS), Actas Capitulares, Tomos 54-55-56 fol. 129 recto

${ }^{75}$ I. GARCÍA RÁMILA, op. cit., p. 105.

76 “El Ilustrísimo Y Reverendísimo Señor Don Fernando de Andrade y Sotomayor, Arzobispo y Señor Seguntino".

77 “Con ardiente celo, levantó la obra y la devolvió hermosa asociando oro y pintura". Traducción tomada de: F. PECES BARBA, Los Obispos en la Ciudad del Doncel. p. 160.
} 
el prelado saliente. En el caso de Andrade y Sotomayor, se sabe que hubo de desembolsar 6.000 reales para la compostura del Castillo de La Riba de Santiuste ${ }^{78}$, a lo que habría que unir "los muchos gastos de expedición de bulas, mudanza de casas, reparos de las fortalezas y casas que dejamos del obispado de Sigüenza, morada de este nuestro arzobispado, resto del coste de Bulas y otros gastos" ${ }^{\prime 79}$, no es extraño que para afrontar esas costas tuviese que pedir a su llegada a Santiago de Compostela un préstamo a don Pedro de Navia, su más estrecho colaborador desde los tiempos en que era arzobispo de Burgos ${ }^{80}$.

En su etapa como arzobispo de Santiago (1645-1655), parece ser que don Fernando de Andrade no promocionó ningún elemento artístico, ya que destinó gran parte de su peculio a las obras que estaba llevando a cabo en Villagarcía de Arosa, aunque sí que dotó la solemnidad del Octavario del Corpus y la Octava de la fiesta del Apóstol.

El objetivo de ambas dotaciones era que "se celebrasen dichas festividades con la devoción y grandeza que refiere dicha dotación" ${ }^{81}$, que ascendía a la suma de 400 ducados: 300 para la festividad del Corpus y 100 para la de Santiago. Este dinero se asentaba sobre parte de los juros de las salinas del Reino de Galicia que don Pedro de Navia había comprado por mandato del prelado, asegurando con ello la continuación de ambas celebraciones ${ }^{82}$.

${ }^{78}$ AHPG, Protocolos de Sigüenza, Oficio de Bernardo Sedeño, 10 de abril de1645, caja 2198, s/f.

${ }^{79}$ F. BOUZA-BREY TRILLO, op, cit., pp. 109-110.

80 Pedro de Navia, era natural de Villagarcía de Arosa y Mayordomo mayor de don Fernando de Andrade durante su pontificado en Burgos, llegó a ser Arcediano de Nendos. Fundó en la iglesia de Santa Eulalia de Arealonga la capilla de San Miguel para su enterramiento y el de sus familiares. Persona de total confianza del prelado, actuaría en numerosas ocasiones en su nombre y en otras le prestaría dinero.

${ }^{81}$ Ibídem, p. 117.

${ }^{82}$ A. LÓPEZ FERREIRO, op. cit., p. 120.
Un último aspecto que permite conocer la personalidad del prelado y los diversos bienes del ajuar litúrgico que poseía es el espolio, que era el proceso mediante el cual se devolvía a la Iglesia los bienes que no pertenecían, a título personal al prelado. Un juez de espolios era el encargado de separarlos a la muerte del resto de pertenencias. Por lo general, formaba parte de ese conjunto las prendas del pontifical y algunos otros objetos litúrgicos, dinero y objetos suntuarios ${ }^{83}$. Una vez separada la parte reservada al nuncio papal, el resto de bienes susceptibles de espolio debían dividirse entre todas las sedes que hubiese ocupado el finado que así lo pidiesen ${ }^{84}$. En el caso de nuestro arzobispo, el proceso fue lento y dificultoso debido al elevado número de instituciones y personas que tenían derecho a tomar parte. Solo algunos de ellos, como el cabildo burgalés, no mostraron interés, ya que "la costumbre de esta iglesia es la de no repartir los pontificales de los espolios de los arzobispos" ${ }^{\prime 85}$, mientras que otras, como la de Palencia, si que requirieron su parte ${ }^{86}$.

Tras su muerte el 22 de enero de 1655 , se recogieron todos los objetos y dinero con vistas a llevar a cabo su reparto. Tres años después, en 1658, Francisco de la Cueva, provisor y gobernador de la diócesis de Santiago, ordenó el recuento, inventario y tasación de los bienes dejados y susceptibles de entrar a formar parte del espolio. La tasación corrió a cargo del platero Bartolomé da Iglesia y el bordador Benito da Mata, mientras que la repartición de los bienes se llevó a cabo el 24 de mayo de 1659 bajo la supervisión de Antonio de Somoza. El proceso fue

\footnotetext{
${ }^{83}$ F. QUILES, op. cit., pp. 245-246.

${ }^{84}$ pp. 245-246.

${ }^{85}$ AHCB, Varios, 7-2, Unidad Documental 82-90 fol.
} $84 \mathrm{v}$.

${ }^{86}$ ACP, Armario I, Legajo I № 38, Relación de las ropas y alhajas del Pontifical del Ilmo. Sr. Andrade que tocaron a la Fábrica de esta Iglesia de la que había sido obispo, Santiago, 31 de junio de 1675 . 
largo y culminó con la entrega de los efectos diez años después, en $1665^{87}$.

Lo entregado a la catedral de Palencia, cuyo coste ascendió a 1.162 reales, permite hacernos una idea de qué clase de objetos formaban parte del ajuar del prelado, ya que allí se mencionan piezas de plata, joyas, vestiduras litúrgicas, frontales etcétera:

- Una salvilla de plata dorada que peso dos marcos cinco onzas y diez y seis Pesos. de echura que monta ciento y ochenta y seis Reales.

-Un ostiario de plata dorado peso dos marcos y medio y media ochava y veinte $y$ quatro reales de plata de echura monta ciento y ochenta y siete Reales.

-Dos anillos de oro que pesan nueve ochavas montan ciento y diez y siete Reales

- Una casulla de chamelote de aguas carmisi con su estola manipulo e singulo en ciento y ochenta Reales.

-Un frontal de tafetan doble carmisi en cien Reales.

- Una bolsa de cañamaso en cinquenta Reales.

-Unos guantes blancos de punto bordados en veinte Reales.

- Una bolsa con sus cordones de damasco carmisi en veinte y dos Reales.

- Una casulla de chamelote berde con su estola y manipulo en ducientos Reales.

-Un gremial blanco de brocatel de plata en cien Reales.

\section{ACCIONES DE PROMOCIÓN ARTÍSTI- CA EN VILLAGARCÍA DE AROSA.}

La localidad gallega de Villagarcía, lugar donde había nacido el arzobispo y solar de su linaje familiar siempre fue su lugar predilecto. En esta línea de promoción personal e intento de acrecentamiento de su Casa hemos de situar la reconstrucción de edificios religiosos locales o la fundación de un convento

\footnotetext{
87 Ibídem.
}

de agustinas recoletas destinado a servir de panteón funerario para él y su linaje.

Poco tiempo después del inicio de las obras en el Pazo de Vista Alegre, don Fernando de Andrade y Sotomayor decidió ampliar la iglesia parroquial de Santa Eulalia de Arealonga ${ }^{88}$. Para ello, el arzobispo otorgó el 14 de marzo de 1652 una escritura de dotación de 2.000 reales $^{89}$. Por su testamento, otorgado tan solo trece días después sabemos que las obras aún no se habían iniciado, aunque si expresaba que parte del edificio iba a sufragar, "la capilla mayor [...] donde fuimos bautizado y mejorar su edificio..."90 A esta campaña constructiva corresponde la organización de la nave, dividida en cuatro tramos por medio de pilastras toscanas y la bóveda de cañón con el intradós trabajado con casetones en resalte, siguiendo el mismo modelo ya utilizado en la iglesia del convento de Vista Alegre ${ }^{91}$ (fig. 8). Como ya expresase Bonet Correa en su día, se puede establecer cierta relación entre ambas construcciones y la obra del arquitecto Fernández Lechuga o alguno de sus seguidores ${ }^{92}$. Aunque entre los deseos del prelado estaba también la de ampliar la cabecera del templo, esto hubo de esperar a que unos años después don Pedro de Navia optase por continuar el proyecto inicial de nuestro prelado

\footnotetext{
88 Esta iglesia ya había sufrido una primera ampliación en 1566 que fue costeada por su antepasado don Rodrigo de Mendoza, deán de Ourense y abad de Te-
} verga.

${ }^{89}$ F. BOUZA-BREY TRILLO, Op. cit, pp. 106-107. Esta es la misma escritura de dotación que ya hemos citado anteriormente por la que entregó 8.000 ducados para las obras del convento de Vista Alegre.

90 F. BOUZA-BREY TRILLO, Op. cit, pp. 106-107.

91 A. GOY DIZ, y M. C. FOLGAR DE LA CALLE, "Melchor de Velasco y la iglesia parroquial de Villagarcía de Arousa. Nuevos datos sobre la Capilla del Rosario", Quintana: Revista de estudios do Departamento de Historia da Arte No 2, 2005, p. 229.

92 A BONET CORREA, op. cit., Es el primero en asociar ambos edificios con la maestría de Bartolomé Fernández Lechuga, hipótesis que han continuado el resto de investigadores. 
y renovar la cabecera, asegurando así la estructura en la que se iba a abrir su capilla funeraria $^{93}$.

Su labor en la zona de Villagarcía parece que alcanzó también a la capilla de la Virgen de Cortegada, priorato medieval dependiente del monasterio de San Martín de Pinario que con posterioridad pasó a manos de la Casa de Vista Alegre ${ }^{94}$. Aunque no se ha encontrado ningún testimonio documental que lo avale, sospechamos que el escudo que preside su portada, similar al del convento de Vista Alegre, es indicativo de que también la renovación de esta fábrica estuvo relacionada con el arzobispo Andrade y Sotomayor. En este sencillo edificio hoy en ruinas, solo destaca su portada, compuesta por un sencillo arco de medio punto entre dos pilastras acanaladas rematadas en frontón triangular (fig.9).

La labor de patrocinio del arzobispo Andrade y Sotomayor culminó con la fundación y construcción de un convento de agustinas junto al pazo familiar, sobre el espacio que ocupaba una pequeña capilla medieval dedicada a San Cristóbal. El propósito fundamental que perseguía con la su creación era, por un lado, servir como lugar de enterramiento para él y su familia, y, por otro, expresar la grandeza y antigüedad de su linaje. En palabras del propio prelado:

[...] siendo nos obispo de la Sancta Yglesia de Sigüenza Haviamos comenzado a edificar como todavía se va edificando la Yglesia de Señor san Christobal Junto a las casas de Vista Alegre donde nacimos, con animo de enterrarnos en ella y esperar allí en compañía de nuestros hermanos, Padres y abuelos el Ultimo Juycio final $[\ldots]^{95}$.

\footnotetext{
${ }^{93}$ A . GOY DIZ, y M. C. FOLGAR DE LA CALLE, op. cit., p. 231.

94 J. SALGADO DE LA RIBA, “Apuntes Históricos sobre la Isla de Cortegada", El Regional, Diario de Lugo № 8190 (29-07-1907), p. 1.

${ }^{95}$ F. BOUZA-BREY TRILLO, op. cit., p. 100.
}

Pero este deseo variaría una vez fue designado arzobispo de Santiago, pues aunque mantuvo la idea inicial de que el convento de Vista Alegre funcionase como panteón familiar, ya en 1651 exponía su deseo de ser enterrado en la propia catedral de Santiago "en la parte y lugar, que los Señores Deán y Cabildo de dicha Santa Iglesia nuestros muy amados hermanos fueren servidos de señalar" con el objetivo de "conseguir la honra de podernos enterrar en ella a sus santísimos pies"96.

Para dotar la fundación, en septiembre de 1645 ordenó a don Pedro de Navia, su más fiel colaborador que, con dinero del propio prelado, comprase juros sobre las salinas del Reino de Galicia que a continuación serían cedidos a la nueva fundación ${ }^{97}$. Con ello, el convento disfrutaría inicialmente de unas rentas anuales de 3.000 ducados, aunque de esa cantidad se debían deducir 790 que se deberían destinar a mantener al médico que habría de asistir a las monjas, un maestro de niños para la propia villa, dos preceptores que enseñasen gramática en Villagarcía y en la villa de Noya, , así como cumplir con la dotación de seis huérfanas ${ }^{98}$. Tras estos primeros pasos, la escritura definitiva de fundación se protocolizó en el Pazo de Vista Alegre el nueve de octubre de 1648. Tres años más tarde, en 1651, las obras habían avanzado notablemente, pues ya se había terminado la iglesia baja, y se estaban culminando las obras de la iglesia alta ${ }^{99}$.

\footnotetext{
96 Ibídem. Se refiere a los pies de la tumba del Apóstol.

97 Ibídem, p. 105.

${ }^{98}$ F. A. DE VILLERINO, Esclarecido solar de las religiosas recoletas de nuestro padre San Agustín y vidas de las insignias hijas de sus conventos Libro XX. Madrid, 16901694, p. 52. El fin de estos 790 ducados era incrementar y mantener la dotación hecha por su antepasado don Rodrigo de Mendoza y las dotaciones del médico y el maestro de niños.

${ }^{99}$ ACP, Copia auténtica de la fundación del Convento de
} San Cristóbal..., Armario III, Legajo 5, № 418 s/f. 
El prelado había reservado para su enterramiento la Capilla del Santo Cristo, de planta cuadrada y cubierta con media naranja, en cuyo lado del Evangelio había mandado "se hiciese un nicho, arco y sepulcro, en el cual fue nuestra voluntad fuese sepultado nuestro cuerpo..."100. En este espacio funerario había mandado colocar un altar y retablo con "un retrato sacado de nuestra orden del que está en el convento de Religiosas del orden de San Agustín de la ciudad de Burgos"101. Este no es otro que el famosísimo Cristo de Burgos, cuya imagen gozó de una amplísima devoción y difusión en todos los reinos hispanos, y que sin duda veneró en su etapa como arzobispo de Burgos. Por desgracia, este retablo fue sustituido por otro de factura más moderna, aunque si se conserva el nicho en el que inicialmente iba a ser enterrado Andrade y Sotomayor, de una gran sobriedad y donde campea su escudo.

Siguiendo esa idea de panteón familiar con que había concebido la iglesia conventual, distribuyó los restos de sus familiares entre los dos espacios de los que constaba el templo: En la iglesia alta o cabecera, mandó hacer a ambos lados del altar mayor dos arcos para colocar los restos de sus abuelos paternos y los de sus padres, mientras que en los nichos de la iglesia baja, o cripta, habrían de ser trasladados los restos de sus tíos paternos y sus hermanos don Jerónimo y Don Pedro de Mendoza. ${ }^{102}$

También dispuso que a su muerte, el patronato del convento quedase en manos del cabeza de la casa de Vista Alegre, y estipulaba que el centro religioso tendría la obligación de acoger perpetuamente sin dote a diez religiosas: siete propuestas por él y tras su muerte por sus sucesores en la Casa de Vista Alegre y una de cada uno de

\footnotetext{
${ }^{100}$ A. LÓPEZ FERREIRO, op. cit., p. 124.

${ }^{101}$ Ibídem.

102 Ibídem.
}

los tres obispados que había ocupado antes del de Santiago ${ }^{103}$

El objetivo de esta segunda disposición era muy claro, crear un espacio donde se pudiesen recoger todas aquellas mujeres de su familia que no se hubiesen casado o fuesen viudas. Esto era algo muy habitual en la época, y permitía dar una salida digna al "exceso" de féminas que habitualmente existía entre las grandes familias sin necesidad de tener que aportar las costosas dotes matrimoniales.

Creadas las dotaciones económicas básicas para la supervivencia del convento, instituido el patronato e iniciado su construcción, el proceso culminaba con la venida de las fundadoras. Andrade y Sotomayor eligió para ello a la orden de las Agustinas Recoletas, muy en auge en aquel tiempo ${ }^{104}$.

Conviene señalar que la relación del prelado con las agustinas recoletas venía ya de su etapa como obispo de Palencia, época en la que mantuvo un estrecho trato con el convento de San Agustín de esa ciudad, situado justo al lado de la catedral ${ }^{105}$. Las escogidas para poblar la nueva fundación fueron cuatro monjas provenientes del convento de San José de Villafranca del Bierzo ${ }^{106}$ : y la

\footnotetext{
103 ACP, Copia auténtica de la fundación del Convento de San Cristóbal..., Armario III, Legajo 5, № 418 s/f. “Porque fue Dios servido que ayamos goçado y tenido tres grandes diócesis en el Reyno de Castilla que son la de Palencia, Burgos y Siguença y que hemos goçado fructos y con parte de lo procedido dellos hicimos se edificase dicha Yglesia alta y vaja que se hiciese la compra y empleo de dicho juro para estas nuestras fundaciones y por otras raçones que nos mueven ordenamos y mandamos que de cada una de dichas Diocesis se admita para religiosa profesa de velo en dicho convento una doncella de buena fama, vida y costumbres [...] perpetuamente, y no se le a de llevar ni pedir dote alguna..."

104 Sobre la Orden de las agustinas recoletas y su historia véase: A. MARTÍNEZ CUESTA, "Monjas Agustinas Recoletas. Historia y Espiritualidad", Acta Ordinis Vol. XXVII, Madrid, 1992, pp. 49-60.

${ }^{105}$ F. A. DE VILLERINO, op. cit., p. 51.

106 Para conocer mejor la historia del convento de San José de Villafranca y el proceso de expansión que
} 
Madre Juana de San Miguel, que fue la primera priora, Mariana de San José, Inés de la Concepción. El 22 de junio de 1652, se otorgó la escritura de entrega que hicieron el arzobispo, su hermano don Mauro, su esposa doña Antonia y el hijo mayor de ambos y heredero don Antonio de Mendoza Caamaño y Sotomayor ${ }^{107}$. Debido a que el convento aún seguía en obras, las monjas se hospedaron en el Cuarto nuevo que se había construido al lado del palacio de Vista Alegre ${ }^{108}$. Sabemos que antes del fallecimiento del prelado el 27 de enero de 1655 , las religiosas ya habían entrado a vivir en el convento, aunque el edificio aún no se había concluido del todo, pues en su codicilo, redactado el 20 de enero de ese mismo año, destinaba 8.000 ducados que deberían sacarse de sus bienes "para fenecer dichas obras" 109 .

El edificio conventual, se asienta al lado del Pazo de Vista Alegre, del que se separa por una callejuela y mediante la que se une por un paso elevado que comunica con una tribuna elevada. Aunque no se conoce la fecha exacta de inicio de los trabajos, sabemos por un documento de 1648 que el arzobispo mandaba:

[...] se acabe de cubrir del todo el edificio de dicha yglesia altar y echo esto se prosiga y acabe la fábrica de la dicha casa y convento junto a la dicha iglesia alta y vaxa [...] según la traça y planta de Maestros que se an echo para dicho edificio y según tenemos comunicado se ha de hacer ${ }^{110}$.

llevó la orden durante el siglo XVII véase: M.D. CAMPOS SÁNCHEZ-BORDONA, "La expansión de las agustinas recoletas en la España del siglo XVII: fundación y construcción del Convento de San José de Villafranca del Bierzo (León)", Fundadores, fundaciones y espacios de vida conventual: nuevas aportaciones al monacato femenino, León, 2005, pp. 787-824.

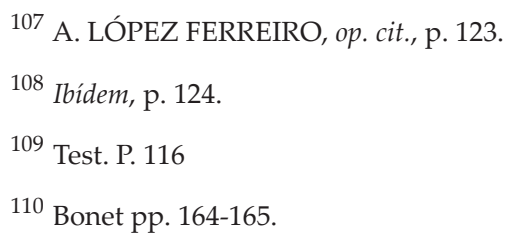

${ }^{110}$ Bonet pp. 164-165.

Aunque no se cita el nombre de ese maestro o maestros autores de la traza, como ya hemos comentado, Bonet Correa apuntó su semejanza con la iglesia de Santa Eulalia de Arealonga y otras obras del arquitecto Bartolomé Fernández Lechuga. Lanzando la hipótesis de que tal vez fuese este arquitecto quien diese las trazas, mientras que de su construcción se encargaría alguno de sus colaboradores, idea que ha sido mantenida por la mayor parte de los estudios posteriores. Nosotros descartamos completamente la autoría y participación directa de Lechuga, ya que el prelado tuvo la idea de crear un convento y comenzó su construcción "siendo nos obispo de la Santa Iglesia de Sigüenza"111, es decir, entre 1640 y 1645, y por lo tanto varios años después de que Fernández Lechuga hubiese abandonado precipitadamente la ciudad de Santiago para no regresar jamás ${ }^{112}$. Por ello, creemos mucho más factible que fuese otro maestro el diseñador del edificio que tendría muy presente la obra que Lechuga había dejado en Galicia.

El espacio conventual consta de un pequeño claustro, alrededor del que se distribuyen las dependencias y una gran iglesia, situada en la zona norte. Este espacio es el más notable y hermoso de todo el conjunto, de planta de una sola nave con tres tramos de capillas laterales, crucero y capilla mayor rectangular entre dos sacristías, todo ello inscrito en un rectángulo. El cajeado presente en las pilastras de orden toscano, las bóvedas y el intradós de la media naranja demuestra la influencia de la obra de Lechuga (fig.10). En el primer tramo de los pies hay un coro alto que se prolonga en las capillas laterales de la nave de bóvedas de arista, y en el tercer tramo del lado de la epístola, se emplaza la Capilla del Santo Cristo que ya hemos mencionado. Las sepulturas del lado de la epístola hoy se hallan convertidas en puertas, pero por lo demás son gemelas a las del lado del Evangelio, con pilastras

\footnotetext{
${ }^{111}$ F. BOUZA-BREY TRILLO, op. cit., p. 100.

112 A BONET CORREA, op. cit., p. 164.
} 
toscanas que encierran un arco de medio punto sobre impostas, lo mismo que su arquivolta. Un frontón recto, con un escudo, campea en su tímpano entre dos triángulos de puntas de diamante. Cada frontón tiene sus tres acróteras con sus correspondientes bolas. A ambos lados de la capilla mayor hay una sepultura de arco de medio punto entre pilastras dóricas, entablamento con friso de triglifos entre metopas lisas y frontón curvo partido para dejar el espacio para las armas de la familia del arzobispo ${ }^{113}$.

Al exterior, la iglesia presenta un hastial con una sencilla portada de arco de medio punto con impostas y pilastras toscanas como las del alzado interior. Sobre su liso entablamento se apea la cornisa que sirve de dintel y sobre la que se levantan dos acróteras adosadas de doble pirámide y bola, elemento típico de Lechuga y sus seguidores ${ }^{114}$. El elemento más destacado de la portada es el gran escudo del prelado, que vuelve a aparecer en el resto de fachadas del convento, mostrando así su patrocinio sobre el edificio (fig.11).

Don Fernando de Andrade dotó de una manera espléndida todo el espacio conventual, y en especial su iglesia. Para ella, contrató en 1642 con el tracista Bernardo Cabrera y el escultor Mateo de Prado su hoy desaparecido retablo mayor ${ }^{115}$, del que conocemos ciertos datos que permiten hacernos una idea de cómo era. Al igual que el Retablo de las Reliquias de la catedral de Santiago que había trazado Cabrera en 1625, tenía columnas salomónicas y "ocho santos de bulto, correspondientes a lo crecido del retablo", entre las que se encontraba el propio patrón del templo, que aún se conserva coronando el retablo dieciochesco actual, y una imagen de Santa Librada de la que, como apuntamos, se había traído una reliquia desde Sigüenza.

\footnotetext{
${ }^{113}$ BONET CORREA, op. cit., pp. 163-164.

${ }^{114}$ Ibídem.

115 Ibídem.
}

En los brazos del crucero se conservan dos retablitos que hasta el momento han pasado bastante desapercibidos por parte de los investigadores. Ambos fueron modificados a finales del siglo XVIII o principios del XIX pero afortunadamente, se conservan suficientes elementos de los originales como para poder adscribirlos al período de mediados del siglo XVII, algo que confirma la presencia de los escudos del arzobispo Andrade y Sotomayor en el coronamiento de ambos.

El del lado del Evangelio, presenta una elegante traza compuesta por tres calles, separadas por columnas de orden corintio que sostienen un frontón partido sobre el que se eleva un ático muy desarrollado que contiene un gran relieve de Santiago en la batalla de Clavijo. En los netos, se representan en relieve y de derecha a izquierda: San Benito, San Agustín, San Bernardo, y Santo Domingo. Aunque se desconoce la autoría de este retablo, en el caso del relieve nos llama mucho la atención las ciertas similitudes que guarda con uno de los sitiales de la Sillería del Coro del monasterio de San Martín Pinario que representa a Santiago Matamoros. Las similitudes se aprecian tanto en la disposición del caballo en corveta, como en las posturas que adoptan algunos de los musulmanes heridos. Esas concordancias se vean más claras en pequeños detalles como el tratamiento de las barbas o las espuelas del santo, lo que nos hace pensar que tal vez este relieve se deba a la gubia del propio Prado, que trabajó en el retablo mayor del convento, o de alguno de sus ayudantes (fig.12).

El segundo retablo, de similar disposición en el primer cuerpo, ha sido mucho más modificado, aunque el segundo cuerpo y el ático, se conservan casi inalterados. La escultura de San Miguel es de una gran calidad, no obstante tampoco en este caso se conocen sus artífices. El cuerpo superior se divide en tres calles, las laterales retranqueadas y separadas de la central por pilastras rehundidas de orden corintio que soportan un frontón triangular y volutas a los lados. 
Aparte de los retablos, Mayor, Santo Cristo y los dos laterales, el arzobispo dotó al convento con "todo lo necesario para su

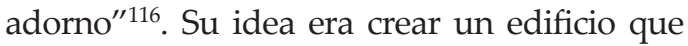
expresase su poder y riqueza, y no solo a través de los múltiples escudos que engalanan sus muros y retablos, sino también a través de las reliquias y piezas artísticas que regaló. Entre las reliquias destacaba la de Santa Librada, que había colocado en un hermoso relicario ${ }^{117}$. Asimismo regaló un rico conjunto de platería compuesto por dos lámparas de plata "de mucho valor", cinco cálices de plata dorada con sus patenas, cuatro juegos de vinajeras con sus salvillas, otro juego de vinajeras grandes, campanillas de plata, una bandeja, un incensario con su naveta y un calderillo de plata, todo "de hechura superior"118. Entre las piezas escultóricas destacaba una Magdalena de bulto, que "había sido hecha en tierra de su sepulcro, reclinada sobre una peña y entre ricos cristales encerrada", lo que parece indicar su procedencia francesa. Además, entregó una rica colección de estampas, láminas y cuadros "de manos de pintores antiguos y celebrados"119, que formarían parte de su colección personal y que vendrían a demostrar su gusto por el arte y su afición al coleccionismo, algo común al resto de la nobleza hispana del momento. Por desgracia en la actualidad desconocemos qué piezas formarían parte de su donación, lo que impide hacer una valoración más profunda de la misma y del gusto artístico del arzobispo.

\section{EL ACRECENTAMIENTO DE LA CASA DE VISTA ALEGRE.}

Por último, vamos a tratar algunos conceptos que resultaban fundamentales

\footnotetext{
${ }^{116}$ F. A. DE VILLERINO, op. cit., p. 53.

117 F. BOUZA-BREY TRILLO “Testamento y codicilo del Arzobispo de Santiago D. Fernando de Andrade y Sotomayor", Boletín da Real Academia Galega, colección de documentos históricos Tomo II, p. 105.

$$
\begin{aligned}
& { }^{118} \text { Ibídem. } \\
& { }^{119} \text { Ibídem. }
\end{aligned}
$$
}

para la nobleza de la época y que sin duda también lo serían para este ilustre eclesiástico: la estirpe y el linaje como elementos articuladores de la vida, fundamentalmente en términos de reproducción y promoción social. El sentimiento de pertenencia a la Casa de Vista Alegre y a su familia siempre fue prioritario para don Fernando de Andrade y Sotomayor. Por ello, no dudó en utilizar en numerosas ocasiones, el dinero derivado de las prebendas que disfrutó para dotar y ayudar a algunos de sus parientes, o contribuir a fortalecer y ampliar el mayorazgo familiar. Esto se dio sobre todo durante el período que lo detentó su sobrino don Rodrigo de Mendoza y Sotomayor (1633-1641). Tras la muerte de don Lope de Mendoza, su padre y poseedor del título, fue el arzobispo Andrade quien se hizo cargo del muchacho, que por entonces contaba con doce años y de su hermano don Fernando de Mendoza ${ }^{120}$, llevándoselos a Burgos donde los educón ${ }^{121}$.

Durante su estancia en Pamplona como Virrey de Navarra y "por justas causas y respectos que nos movieron"122 entregó a su sobrino dos series de tapices, una compuesta por siete piezas, que narraba la historia de Cleopatra y la otra, de ocho, con la representación de la historia del Cónsul Lelio, así como dos fuentes de plata y otras dos piezas de plata doradas que el obispo tenía consigo desde su anterior estancia como canónigo de Sevilla, piezas "que por antiguas y por su hechura merecían estimación"123.

\footnotetext{
120 Don Fernando de Mendoza detentó el señorío y mayorazgo de Villagarcía, Casas de Barrantes y vista Alegre entre 1641 y 1644, año en que falleció.

${ }^{121}$ F. BOUZA-BREY TRILLO, El Señorío de Villagarcía desde su fundación hasta su marquesado (1461-1655), Santiago de Compostela, 1965, p. 88.

122 F. BOUZA-BREY TRILLO, “Testamento y codicilo del Arzobispo de Santiago D. Fernando de Andrade y Sotomayor", Boletín da Real Academia Galega, colección de documentos históricos Tomo II, p. 111.

${ }^{123}$ Ibídem, p. 112. Conocemos qué otros objetos de plata formaban parte de esa dotación gracias a un listado posterior que consigna todos los objetos que entregó el prelado para sus familiares:“[...]18 platos tunescos
} 
Con ello se demuestra la afición del prelado por el coleccionismo de tapices, piezas habituales en las casas e interiores domésticos nobiliarios. Las series de tapices mencionadas las había adquirido en la propia ciudad de Pamplona del Padre fray José Gallo $^{124}$. En la actualidad se desconoce si aún se conservan, existen en España series muy similares que permiten hacernos una idea de su apariencia, como las serie de Marco Antonio y Cleopatra de la catedral de Burgos, basada en cartones atribuidos a Pieter Coecke y realizada posiblemente en Bruselas en la segunda mitad del siglo $\mathrm{XVI}^{125}$.

La voluntad del prelado de que fuera su sobrino el encargado de custodiar estas obras artísticas se vio frustrada, ya que debido a su marcha a la guerra contra Francia y posterior fallecimiento en 1641, no fue posible. Por ello cuando Andrade dictó su último testamento en 1652 mandó que a su muerte se llevasen al Pazo de Vista Alegre y se entregasen a su hermano don Mauro, que por aquél entonces detentaba el mayorazgo a fin de que quedaran vinculadas a la familia ${ }^{126}$.

Asimismo, mientras residió en el palacio arzobispal de Burgos Andrade y Sotomayor también disfrutó en sus estancias de otras dos series de tapices propiedad de su sobrino don Rodrigo: una compuesta por seis piezas con el tema de la historia de Tobías y otra de tres con la de Moisés que habían sido comprados con el dinero de su cuñada doña Juana de Moscoso al provisor del arzobispado de Burgos Don Juan Ibáñez de Carvajal $^{127}$.

(sic.) de plata, dos medianos y dos mayores, salero, pimentero y azucarero dorado, dos fuentes doradas, dos jarros dorados, dos tazas gallegas que sirven de salvas doradas que todo esto dorado es lo que está vinculado"

124 F. BOUZA-BREY TRILLO, op. cit., p. 89.

125 http://www.flandesenhispania.org/tapices/ index.php/Serie_Marco_Antonio_y_Cleopatra. Consultado el 28 de abril de 2013 a las 23:51 horas.

126 F. BOUZA-BREY TRILLO, op. cit., pp. 111-112.

127 I. GARCÍA RÁMILA, op. cit., p. 27.
Parece ser que también fue muy inclinado a la exaltación de su propio linaje, respondiendo a tal motivo "unos retratos de nuestros mayores, hermanos y deudos que hemos hecho hacer en esta ciudad"128 que a modo de galería de hombres ilustres guardaba en sus aposentos. También en esta ocasión el arzobispo encargaba a sus testamentarios que se entregasen a su sobrino don Rodrigo, aunque por los mismos motivos ya señalados la entrega fue posterior ${ }^{129}$.

Fallecido el prelado, los tapices, objetos de platería y retratos ingresaron en el vínculo del mayorazgo. Su destino fue decorar el conocido como Salón noble donde estuvieron hasta mediados del siglo XIX, siguiendo el modelo por él ideado ${ }^{130}$. Todo este conjunto artístico es un claro indicio de su gusto por el arte, el lujo y la ostentación, algo común al resto de la nobleza de la época, en cuyos inventarios se encuentran casi siempre piezas similares. De todas las referencias citadas se desprende que la relación con su sobrino Rodrigo de Mendoza fue siempre fue muy estrecha y considerándolo el verdadero heredero de la Casa y linaje.

También vinculó al mayorazgo todo su archivo, con el objetivo de dar testimonio de la grandeza de su linaje y el servicio, amor y lealtad que tanto él como sus familiares demostraron a la monarquía y obtener el favor real en la figura de su hermano don Mauro y sus sucesores ${ }^{131}$ :

${ }^{128}$ Ibídem, p. 27.

${ }^{129}$ F. BOUZA-BREY TRILLO, op. cit., pp. 98 a 120.

${ }^{130}$ F. BOUZA-BREY TRILLO, “Un pazo galego nos séculos XVI e XVII", Boletín de la Real Academia Galega, № 177, 1925, p. 211. “Mas seis mil tachuelas para clavar los lienços en sus marcos y Mas una tablilla larga con sus cortinillas verdes en que van unos retraticos pequeños que sirva de modelo para poner los retratos en Vista Alegre." P. 218.

131 "todo lo qual Su Magestad fue servido Reconozer y aprobar por muchas cartas suyas y otras de sus Mayores ministros que tenemos y dejamos a la casa de nuestros padres donde nacimos por prendas desta Verdad esperando que los subcesores en ella han de conseguir y merecer la continuada gracia del Rey nuestro 
Se ha conservado un listado que incluye todas las dádivas que el prelado dejó a sus familiares, y entre ellas un somero inventario de su archivo personal entre cuyos libros y documentos podemos destacar dos tomos de la Política de Bobadilla, la Genealogía de los Caamaños, Diez y seis "cuerpos de libros" de cartas escritas por los Condes de Lemos y otros personajes de la nobleza para nuestro prelado, un libro con los despachos militares que dio durante su gobierno como Virrey de Navarra, diversos árboles de Genealogía, la Relacion de la expulsión de los Moros del Reino de Valencia, varios testamentos familiares, siete libros de "diversos manifiestos y papeles curiosos" relacionados con las guerras entre España y Francia, diez y seis libros "de humanidad muy curiosos y de antigüedad en diversas lenguas ${ }^{132}$.

Ello nos permite saber que don Fernando de Andrade y Sotomayor era un personaje sumamente culto y muy bien relacionado en las altas esferas políticas hispanas.

Pero la largueza del prelado con su solar y familia no quedó ahí, ya que dejó numerosos bienes a varios de sus familiares y personas próximas. A las mujeres esencialmente prendas, piezas textiles y pequeños enseres femeninos y a don Pedro de Navia ornamentos litúrgicos. Por su parte, a los miembros masculinos, su sobrino don Rodrigo y su hermano don Mauro les entregó un conjunto más nutrido de bienes artísticos y de mobiliario que son muestra de una típica colección de la nobleza del siglo XVII:

Un escritorio de carey llenos los caxones de diferentes buxerías, una escribanía de Mano, con su adereço entero de plata y sello de cristal y oro con sus armas y una frasquerilla de

Señor, [...] muy Humildemente suplicamos a su Magestad que $[. .$.$] se sirva de honrar a la casa de Vista alegre$ [...] en la persona de Don Mauro de Mendoza y Sotomayor nuestro hermano."

132 F. BOUZA BREY TRILLO, op. cit., pp. 218-219. El estudio y análisis pormenorizado de su biblioteca y archivo personales quedan pendientes a la espera de la realización de un trabajo monográfico sobre los mismos. caray con ocho frascos de vidrio con bocales de plata para aguas de rostro [...]

Y una piedra Bezar grande de estimaçion [...]

Armas y una rodela grabada de Jaujía que corresponde con las armas que estan allá133.

La última aportación que hizo al linaje familiar fue lograr que el rey Felipe IV le concediese el 23 de junio de 1654 el título de Marqués de Villagarcía y el Vizcondado de Barrantes, título que inmediatamente cedió a su hermano menor don Mauro de Mendoza.

[...] por los muchos, buenos y agradables servicios que a mi me ha hecho y hace continuamente en utilidad conocida de lo que ha corrido y corre por sus manos [...] socorriendo en diferentes ocasiones con gente, donativos y bastimentos para mis exércitos de que me he dado y doy por muy servido ${ }^{134}$.

A tenor de todo lo anteriormente expuesto, podemos concluir diciendo que la figura de don Fernando de Andrade y Sotomayor y su relación con las artes constituye un claro ejemplo de lo que todo un conjunto de prelados y nobles llevaron a cabo durante el reinado de Felipe IV, compartiendo idénticos fines a los de nuestro protagonista, por un lado la promoción social y exaltación del linaje a través de la concesión de favores y puestos por parte a miembros del mismo, y por otro un interés real por el fomento y protección de las artes o la cultura.

\footnotetext{
${ }^{133}$ F. BOUZA-BREY TRILLO, op. cit., pp. 218-219.

${ }^{134}$ F. BOUZA-BREY TRILLO, El Señorío de Villagarcía desde su fundación hasta su marquesado (1461-1655), Santiago de Compostela, 1965, pp. 90-91.
} 


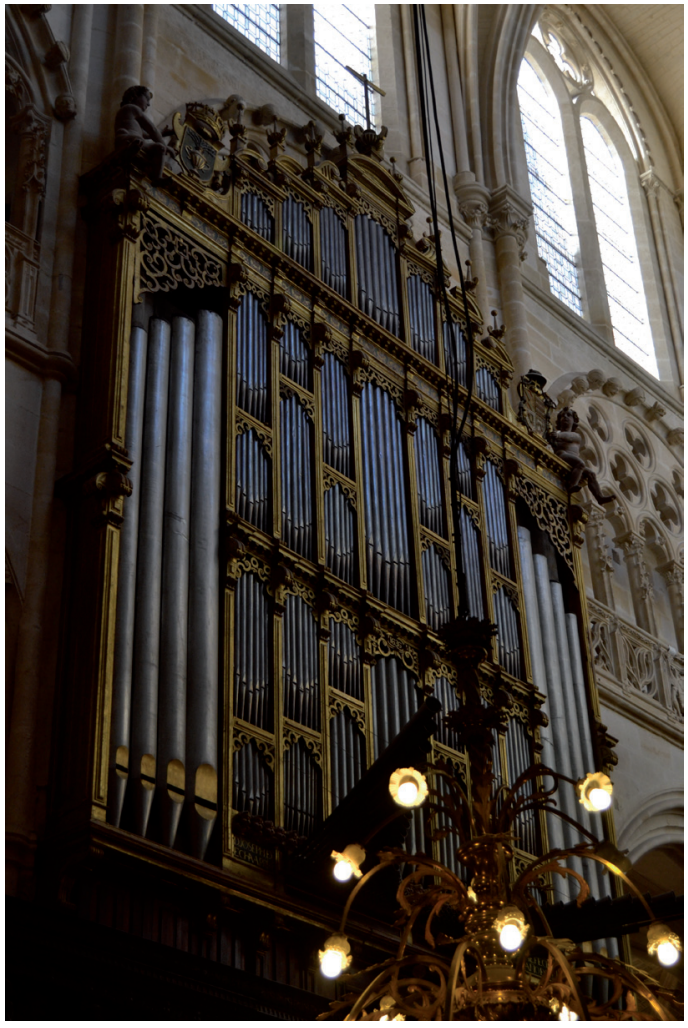

- Fig.1. Caja del órgano de la Epístola de la catedral de Burgos, obra de Juan de Argüete. (Foto del autor).

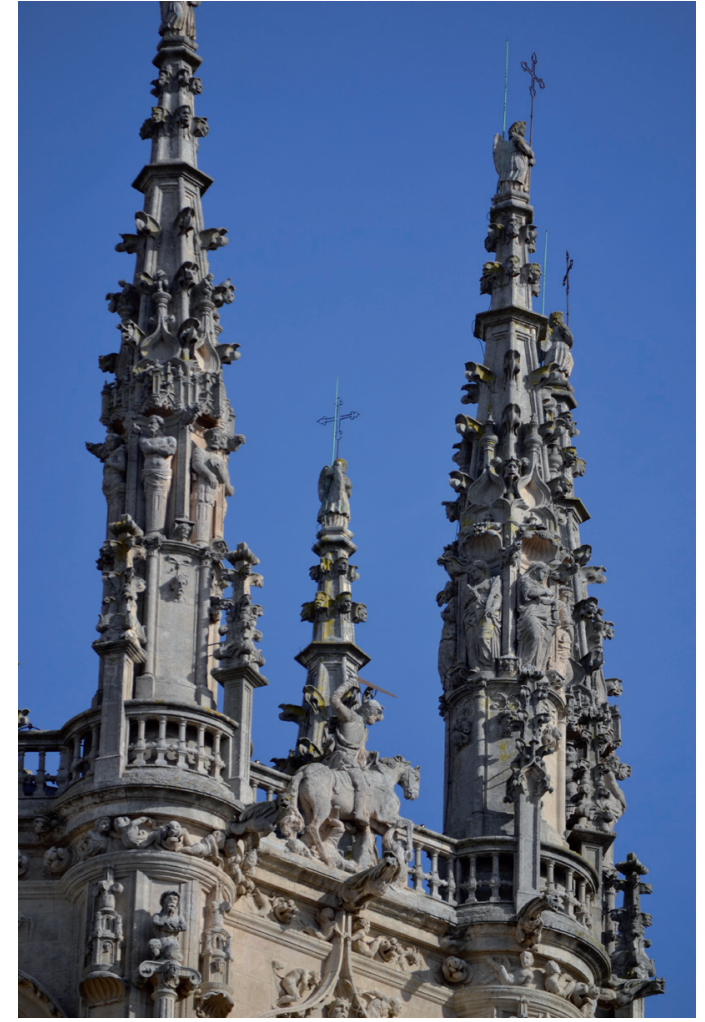

- Fig.3. Detalle del cimborrio de la catedral de Burgos con los pináculos y esculturas reconstruidos en 1642. (Foto del autor).

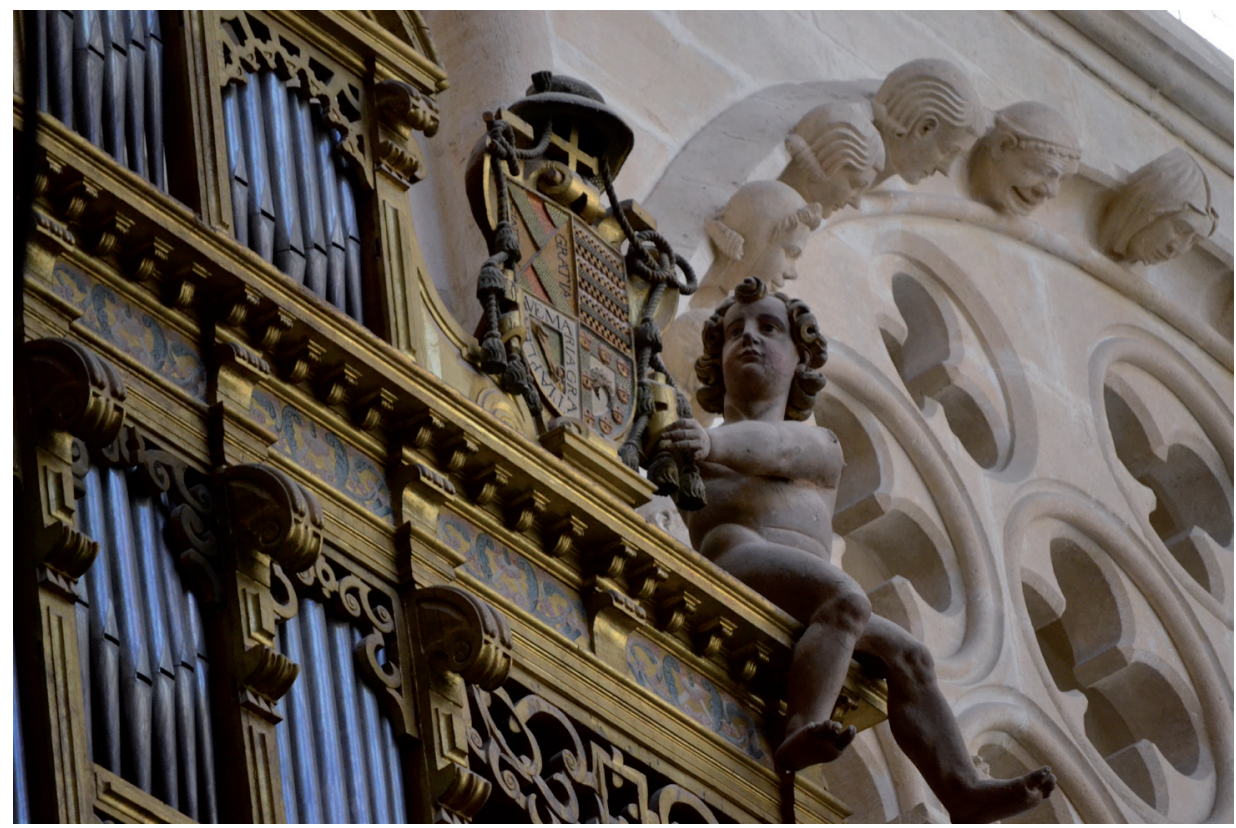

- Fig.2. Detalle del órgano de la Epístola de la catedral de Burgos con el escudo del arzobispo don Fernando de Andrade y Sotomayor. (Foto del autor). 


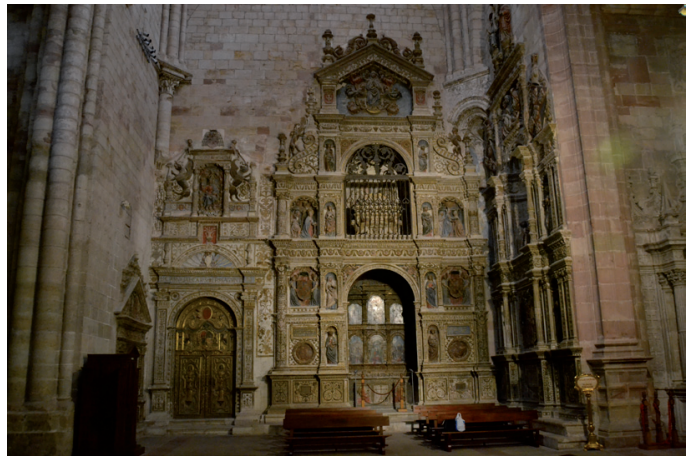

- Fig.4. Vista de la Capilla de Santa Leocadia de la catedral de Sigüenza. (Foto del autor).

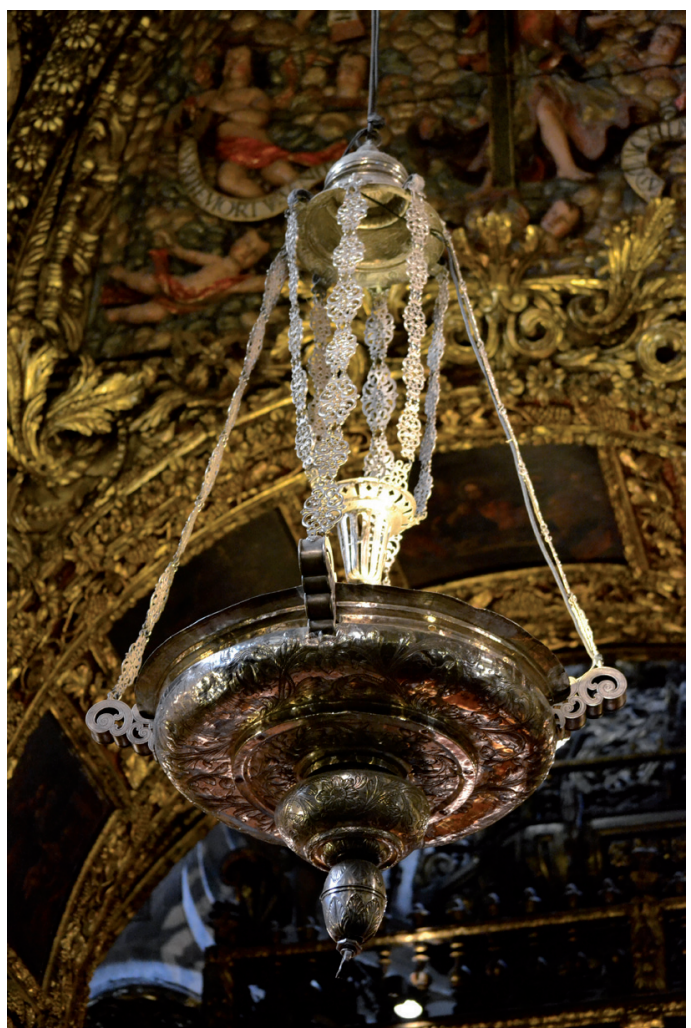

- Fig.6. Lámpara regalada por don Fernando de Andrade y Sotomayor en la Capilla del Santo Cristo de Orense. (Foto del autor).

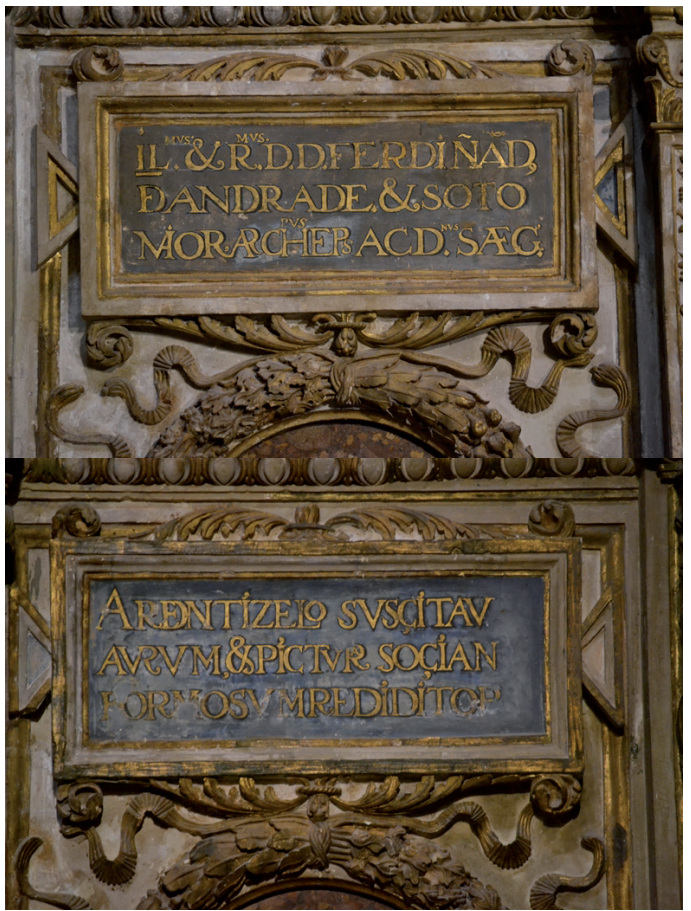

- Fig.5. Cartelas con inscripciones alusivas a las obras de restauración emprendidas por don Fernando de Andrade y Sotomayor en la capilla de Santa Leocadia de la catedral de Sigüenza. (Foto del autor).

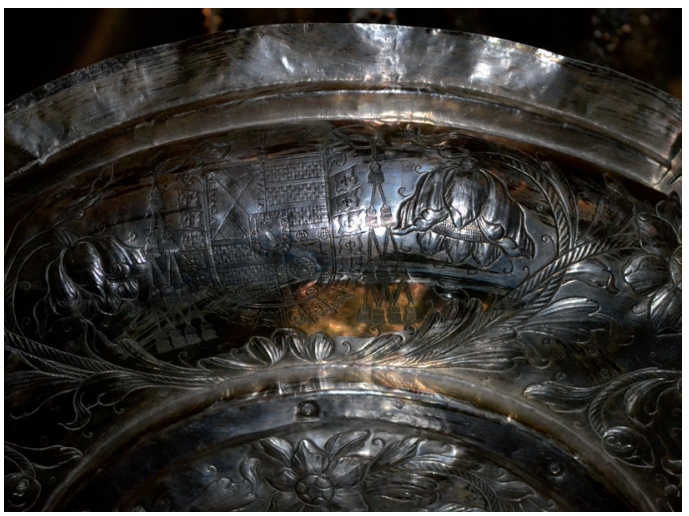

- Fig.7. Detalle de la lámpara de la Capilla del Santo Cristo de Orense con el escudo del arzobispo Andrade y Sotomayor. (Foto del autor). 


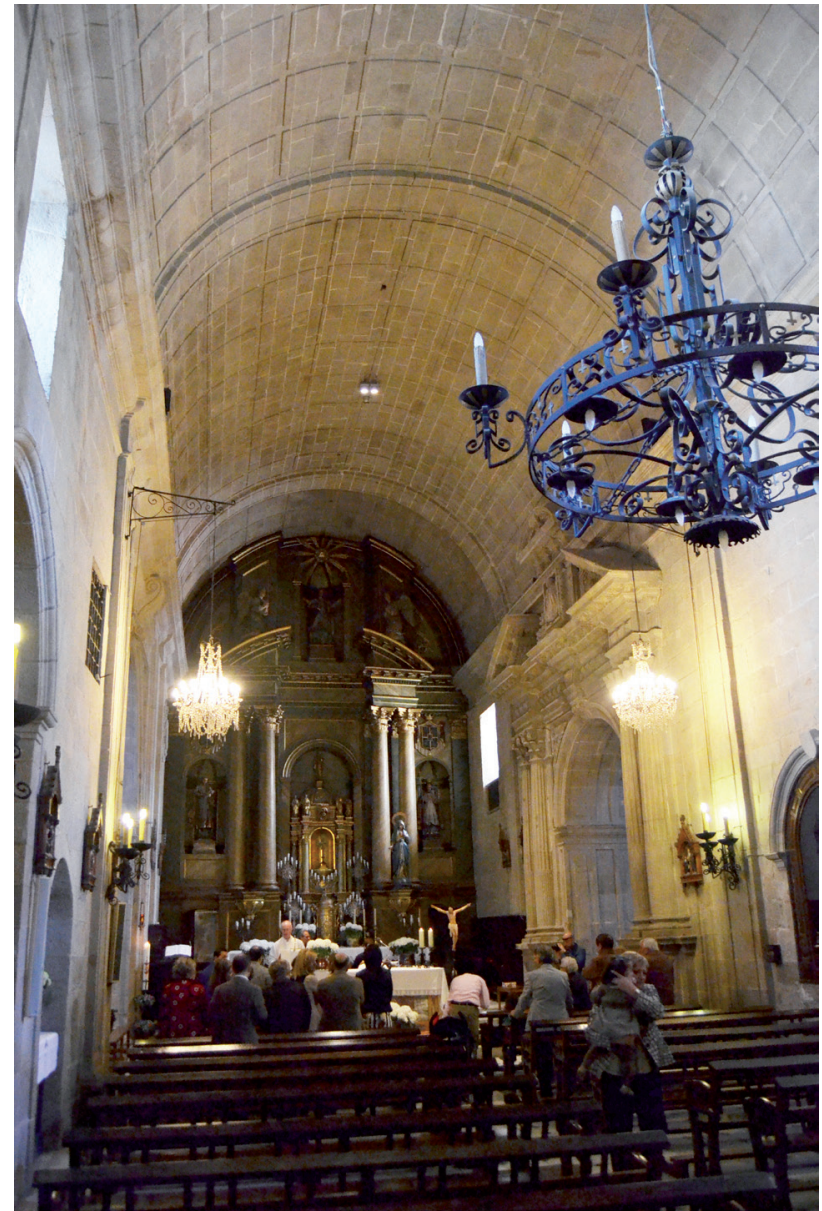

- Fig.8. Vista desde los pies del interior de la iglesia parroquial de Santa Eulalia de Arealonga mostrando la ampliación llevada a cabo por el arzobispo Andrade y Sotomayor. (Foto del Autor).

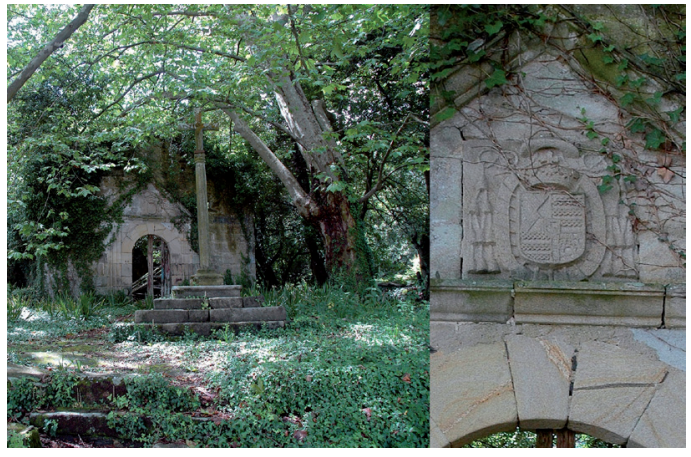

- Fig.9. Ruinas de la capilla de Nuestra Señora de Cortegada y detalle del escudo del arzobispo don Fernando de Andrade y Sotomayor sito en su portada. (Foto del autor).

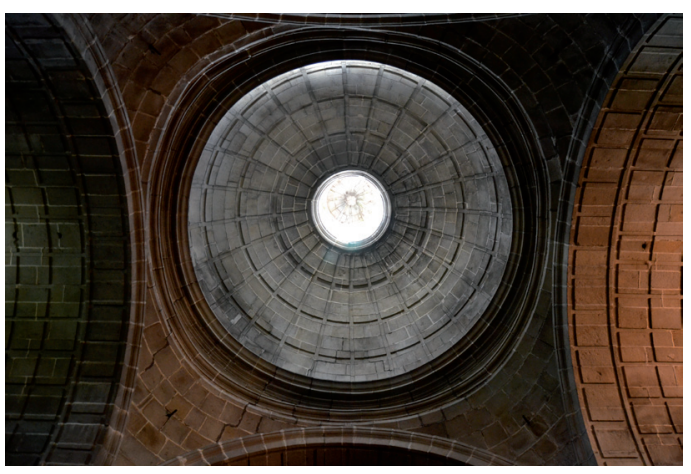

- Fig.10. Bóvedas y media naranja de la iglesia del convento de Vista Alegre. (Foto del autor). 


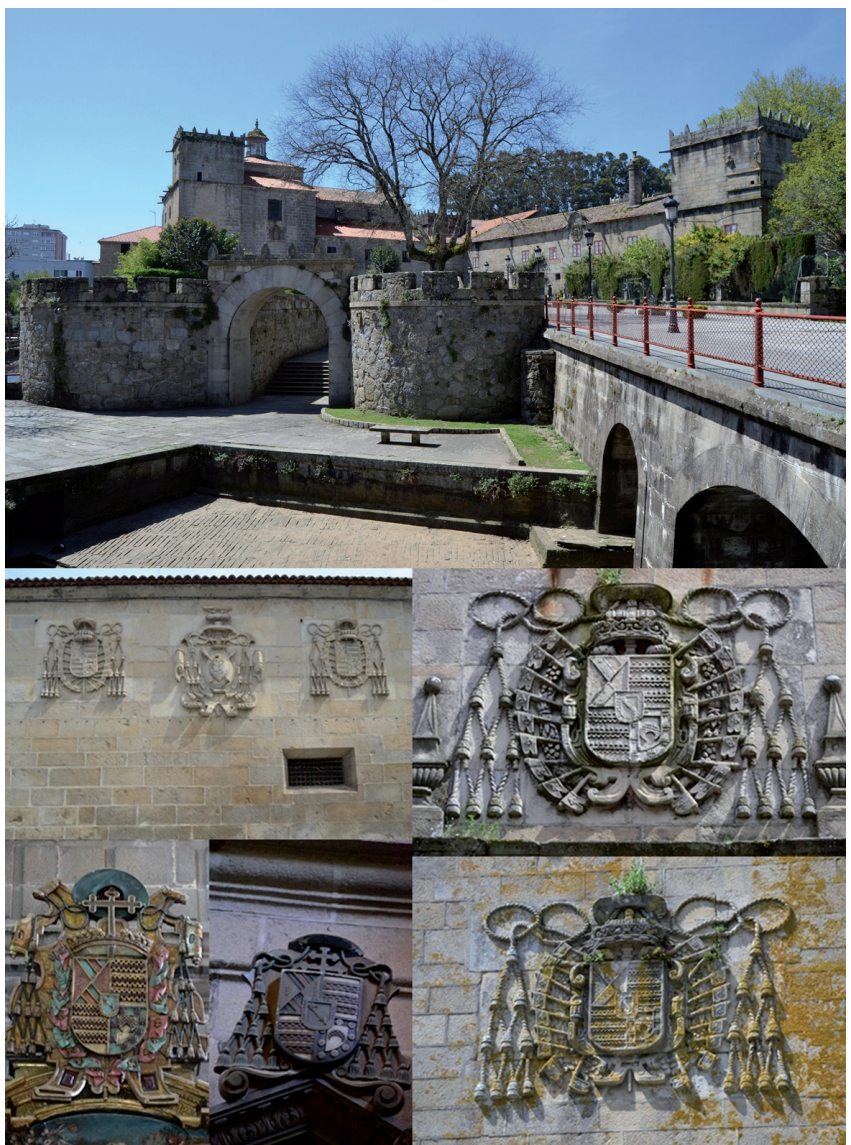

- Fig.11. Vista del Pazo y Convento de Vista Alegre y fotografías de escudos de don Fernando de Andrade y Sotomayor que decoran los muros exteriores del convento de Vista Alegre. (Foto del autor).

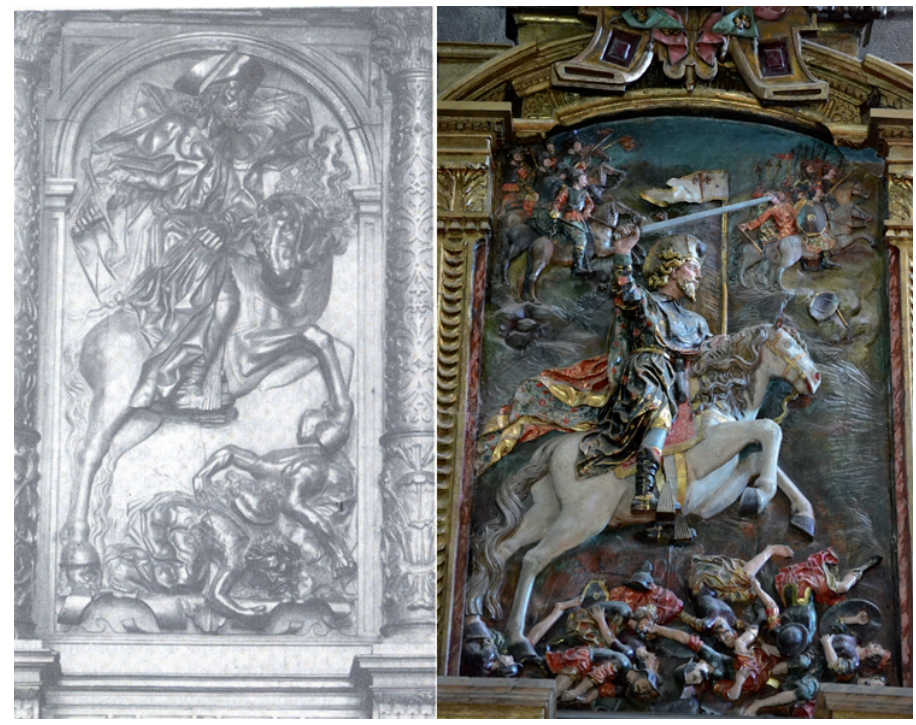

- Fig.12. Relieves de la Batalla de Clavijo del retablo del Evangelio de la iglesia del convento de Vista Alegre (Foto del autor), y Santiago Matamoros de la sillería de San Martín Pinario, publicado por J.J. Martín González, Escultura barroca en España 1600-1770, Madrid, 1998. 